$\underline{\text { Review Article }}$

\title{
OVERVIEW ON FLOATING DRUG DELIVERY SYSTEM
}

\section{MIRMEERA GIRISH NIHARIKA1, KANNAN KRISHNAMOORTHY*2, MADHUKAR AKKALA ${ }^{1}$}

1Avanthi Institute of Pharmaceutical Sciences, JNTUH, Hyderabad, Telangana, India, 2Department of Pharmacy, Annamalai University, Annamalai Nagar, Tamilnadu, India

Email: egkkannan@yahoo.co.in

Received: 26 Jul 2018, Revised and Accepted: 04 Oct 2018

\section{ABSTRACT}

The principal objective behind the writing of this article on the floating drug delivery system (FDDS) was to systematize the recent literature with the core process of floatation in acquiring gastric retention. The different strategies used in the development of FDDS by constructing the effervescent and noneffervescent type of floating tablets basis of which is buoyancy mechanism. FDDS is a method to deliver the drugs that are active locally with a narrow absorption window in the upper gastrointestinal tract, unstable in the lower intestinal environment, and possess low solubility with higher $\mathrm{pH}$ values. The novel methodologies in FDDS include approaches to design a single unit and multiple-unit floating systems, the physiological and formulation variability affecting gastric retention along with the use of recently invented and developed polymers. This review also focuses on various in vitro techniques and in vivo studies in view of performance and application of floating systems. Floating dosage forms can be delivered in conventional forms like tablets, capsules with the addition of suitable ingredients along with the gas generating agent. This review also throws light on different techniques used in developing floating dosage forms along with current and novel advancements.

Keywords: Floating drug delivery systems, Gastric retention, Mechanism, Single unit, Multiple units

(C) 2018 The Authors. Published by Innovare Academic Sciences Pvt Ltd. This is an open-access article under the CC BY license (http://creativecommons.org/licenses/by/4.0/) DOI: http://dx.doi.org/10.22159/ijap.2018v10i6.28274

\section{INTRODUCTION}

Floating drug delivery systems (FDDS) are invented to retain the drug in the stomach and applicable for drugs with poor solubility and low stability in intestinal fluids. The basis behind FDDS is making the dosage form less dense than the gastric fluids to make it float on them. FDDS are hydro-dynamically controlled low-density systems with sufficient buoyancy to float over the gastric contents and remain buoyant in the stomach without affecting the gastric emptying rate for a prolonged period of time. The residual system is emptied from the stomach with the release of the drug. This results in enhanced gastric residence time and good control over plasma drug concentration fluctuations. The principle of buoyant preparation offers a simple and practical approach to achieve increased gastric residence time for the dosage form and sustained drug release [1]. Prolonging the gastric retention of a delivery system is desirable for achieving the greater therapeutic efficacy of the drug substance under certain circumstances. For example, drugs which show better absorption at the proximal part of the gastrointestinal tract and drugs with low solubility and get degraded in alkaline $\mathrm{pH}$ found efficient in prolonging gastric retention. In addition, for sustained drug delivery to the stomach and proximal small intestine in treating certain ulcerative conditions, prolong gastric retention of the therapeutic moiety and hence offer numerous advantages including improved bioavailability and therapeutic efficacy with reduction of dosing frequency [2]. Fig. 1 describes the classification of FDDS with consideration of its physiochemical behavior and appearance.

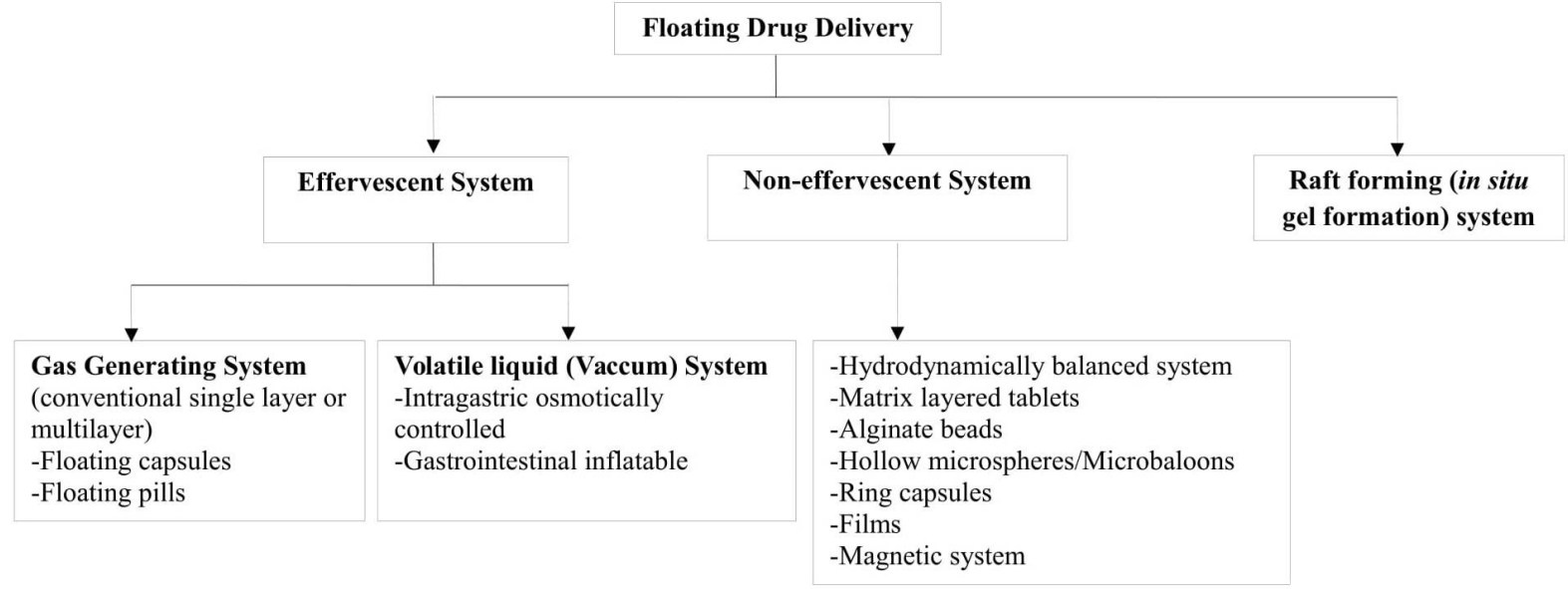

Fig. 1: Classification of floating drug delivery system (FDDS)

This review article is written based on the literature available from 1991 to 2018 and collected by different sources like Pubmed, Google search, Directory of Open Access Journals, Science direct etc. using key words like Floating drug delivery systems, gastric retention, mechanism, single unit, multiple units.

\section{Advantages of floating drug delivery system}

Floating dosage systems are delivery systems with gastric retentive behavior and offer several advantages in drug delivery. Some of these include: 
1. Simple and conventional technique for formulation.

2. Site-specific drug delivery.

3. Controlled delivery of drugs.

4. Delivery of drugs for residual action at a specific site in the stomach.

5. Improved drug absorption with increased GRT and excess duration of contact of dosage regimen at its target site.

6. Minimizing irritation of GIT mucosa by the drugs with slow release rate. Acidic drug substances like aspirin cause irritation to gastric mucosa as it comes in contact. Hence HBS formulation would be beneficial in administration of aspirin and other similar drugs. Administration of prolonged release floating dosage forms, tablet or capsules, causes dissolution of the drug in the gastric fluid. They dissolve in the gastric fluid before getting absorbed in the small intestine with emptying stomach contents. Hence it is expected that a drug will be fully absorbed from floating dosage forms if it remains in the solution form even at the alkaline $\mathrm{pH}$ of the intestine.

7. When there would be vigorous intestinal movement with short transit time, it might result in a certain type of diarrhea hence poor absorption is expected. Under such conditions, it is advantageous to maintain the drug in floating condition in the stomach for better efficacy.
8. In treating gastroesophageal reflux disorders (GERD).

9. Ease of administration with higher patient compliance.

The floating drug delivery system also carries certain disadvantages which limit its applicability [3].

\section{Disadvantages of floating drug delivery system}

1. The major disadvantage of a floating system is due to the necessity of a sufficient level of gastric fluids to float without a sink. However, this limitation can be overcome by coating the dosage form with bio adhesive polymers that easily adhere to gastric mucosa.

2. The drugs those get significantly absorbed throughout gastrointestinal tract, with significant first-pass metabolism, are desirable candidate predominantly.

3. Certain drugs present in the floating system may causes irritation to gastric mucosal linings.

4. Gastric emptying of floating systems may occur at random and highly dependent on its dimensions. Therefore patients should not have dosage prior going to bed.

Table 1 illustrates different parameters in the differentiation of Conventional v/s Gastro retentive drug delivery system

Table 1: Conventional v/s gastroretentive drug delivery system

\begin{tabular}{llll}
\hline Relative parameters & Conventional drug delivery system & Gastro retentive drug delivery system & References \\
\hline Toxicity & High risk of toxicity & Very low risk of toxicity & {$[3]$} \\
Patient compliance & Low & Improved & {$[3]$} \\
Drugs with poor & Not suitable for delivery of drugs with narrow & Suitable for delivery of drugs with narrow & [4] \\
solubility and high pH & absorption window in the Small intestine region & absorption window in the small Intestine region. & \\
Drugs acting locally & Not much advantageous for drugs having rapid & Very much advantageous of drugs acting locally & [4] \\
acting in the stomach & absorption through GlT & in the stomach. & \\
Dose dumping & No risk of dose dumping. & Possibility of dose dumping & [3] \\
\hline
\end{tabular}

\section{Physiological considerations}

Different physiological factors such as $\mathrm{pH}$, gastric enzymes, nature and volume of gastric secretions, residence time, and effective absorbing surface area at the site of delivery contribute the major role in drug execution and absorption. The gastric $\mathrm{pH}$ frequently affects the performance of orally administered drug and it is influenced by various factors like diet, disease, the presence of gases, fatty acids and other fermentation products in the stomach. Radio telemetry has been successfully used in measuring the gastrointestinal $\mathrm{pH}$ in a human being. The reported mean value of gastric $\mathrm{pH}$ in fasted healthy subjects is $1.1 \pm 0.15$, and the mean gastric $\mathrm{pH}$ in fed state in healthy males has been reported to be $3.6 \pm 0.4$. This $\mathrm{pH}$ returns to the basal level in about 2 to $4 \mathrm{~h}$.

Age is the second factor and pathological conditions which influence gastric pH. About $20 \%$ of the elderly people exhibit either diminished (hypochlorhydria) or no gastric acid secretion (achlorhydria) leading to basal $\mathrm{pH}$ value over 5.0. Pernicious anaemia and AIDS are the syndromes in which there is significantly reduction in gastric acid secretion leading to elevated gastric $\mathrm{pH}$. Administration of drugs like $\mathrm{H} 2$ receptor antagonist and proton pump inhibitors significantly reduce gastric acid secretion. The mean $\mathrm{pH}$ value in fasted duodenum has been reported to be $5.8 \pm 0.3$ in healthy subjects, and the fasted small intestine $\mathrm{pH}$ is reported to be $6.0 \pm 0.14$. Normal gastric time usually ranges between $5 \mathrm{~min}$ to 2 h. In consideration of fasted and fed condition of the stomach, two distinct patterns of gastrointestinal motility and secretions have been studied. In a fasted state the electrical activity of the gastrointestinal tract is evidenced by some cyclic contractile events, in the medical language, it is known as migrating myoelectric complexes (MMC) [5].

There are four successive phases of MMC activity as-

Phase I-period of no contraction (30 to $60 \mathrm{~min}$ )

Phase II- a period of intermittent contractions (20-40 min).
Phase III- a period of regular contractions at the maximal frequency that travels distally also known as housekeeper wave (10 to $20 \mathrm{~min}$ )

Phase IV-period of transition between phase III and phase I ( 0 to $5 \mathrm{~min}$ ).

These cycles are retarded by feeding and results into irregular contractile activities which may last for 3 to $4 \mathrm{~h}$. Thus frequent feeding results in prolonging gastric residence time. Another crucial factor in affecting the gastric emptying is the caloric presence in the meals. Fatty and lipoidal contents are emptied at a slower rate than other contents. Acidity and osmolality also contribute major role in lowering the gastric emptying. Stress considered as a factor in gastric emptying rate, while depression lowers it. In general, women and the elderly have a slower emptying rate than men and young people respectively. In addition, exercise and body posture also affect the gastric emptying. Apart from these physiological constraints other factors like size and density of the dosage form also contribute major role in gastrointestinal emptying. Dosage forms possessing low dense character than that of gastric fluid does have properties of floating behavior and gastric retention. A density of $<1.0 \mathrm{gm} / \mathrm{cm} 3$ is necessary for floating phenomenon. Dosage forms with a diameter more than $7.5 \mathrm{~mm}$ exhibits a better gastric residence time [5].

\section{Criteria selection of drug candidate for the floating drug delivery system}

1. Readily absorption via upper gastrointestinal tract.

2. Drugs with low $\mathrm{pKa}$, that does exhibit unionized characters

3. Drugs are possessing lower solubility at higher $\mathrm{pH}$.

4. Effect of local action of drugs e. g. treating Helicobacter pylori in treatment of ulcerative conditions.

5. Drugs which get degraded in alkaline $\mathrm{pH}$ conditions; bioavailability of those can be enhanced by fabricating into gastroretentive forms. 
6. Minimizing gastric irritation as it may result in the increase of drug concentration level in the stomach. $[6,7]$

\section{Limitations of floating drug delivery system}

1. FDDS need to be administered after the meal but the residence and emptying time of drugs depends upon the digestive state which affects its absorption.

2. Floating ability depends on the hydration state of the dosage form. It is necessary of administration of water intermittent (a tumbler full, every $2 \mathrm{~h}$ ) to keep these tablets floating in vivo.

3. Floating ability of drug in the stomach depends upon the person being positioned.

4. Drugs with solubility or stability problems with the gastric fluid are not a suitable candidate for FDDS.

5. Certain drugs though readily get absorbed in the stomach with successful first pass metabolism are not suitable as slow gastric emptying may lead to the reduced systemic bio-availability e. g. Nifedipine $[4,6,7]$.

\section{Application of floating drug delivery system}

1. FDDS are claimed for the increased efficacy of drugs as recent studies show that the administration of Diltiazem floating tablets twice a day would be more effective compared to normal tablets in hypertensive patients.

2. In case of Parkinson patient, FDDS is effective in absorption of the drug over a period of 6-8 $\mathrm{h}$ and maintained substantial plasma concentration.

3. FDDS is site-specific drug delivery: These systems are particularly advantageous for drugs that are specifically absorbed from the stomach or the proximal part of the small intestine, e. g., Riboflavin and Furosemide.

4. FDDS served as an excellent drug delivery system in the eradication of Helicobacter pylori, blamed for chronic gastritis and peptic ulcers.

5. FDDS are perfect HBS dosage form to provide better delivery of drugs and reduced its GI side effects. [6-8]

Table 2 shows the different polymers used in the floating drug delivery system and their effects

Table 2: View of different polymers used and their effect in floating

\begin{tabular}{|c|c|c|c|}
\hline Drug & Polymer used & Floating effect & Reference \\
\hline Ondansetron & EudragitS100 & The drug release rate and floating behavior both were reported good & [9] \\
\hline Captopril & Eudragit & $\begin{array}{l}\text { A good floating behavior was observed, whereas the dissolution rate was found } \\
\text { to be slow, because of the low solubility of Eudragit at acidic } \mathrm{pH}\end{array}$ & [10] \\
\hline Risperidone & Eudragit & $\begin{array}{l}\text { A good floating behavior was observed, whereas the dissolution rate was found } \\
\text { to be slow, because of the low solubility of Eudragit at acidic } \mathrm{pH}\end{array}$ & [11] \\
\hline Ofloxacin & Eudragit & The floating was reported for more than $24 \mathrm{~h}$. & [12] \\
\hline Cephalexin & HPMC & Longer gastric residence time and improved bioavailability & [13] \\
\hline Hydralazine & HPMC & Sustained release pattern with good swelling index and floating effect & [14] \\
\hline Simvastatin & HPMC & More sustained drug release with high buoyancies & [15] \\
\hline $\begin{array}{l}\text { Cefpodoxime } \\
\text { proxetil }\end{array}$ & HPMC-Guar gum & Floating lag time enhanced with an increase in swelling behavior & [16] \\
\hline Atenolol & HPMC-Locust bean gum & Follows zero order kinetics with prolonging the gastric residence time & [17] \\
\hline Diltiazem & Sodium alginate beads & Sustained drug delivery over a period of time with a reduction in dose frequency & [18] \\
\hline Ranitidine & $\begin{array}{l}\text { Polyacrylate, HPMC and } \\
\text { chitosan gel }\end{array}$ & Sustained drug delivery with increased swelling behavior & [19] \\
\hline Ciprofloxacin & EC and HPMC & Increased gastric residence time with a decrease in dose amount and interval & [20] \\
\hline Propranolol & Polyvinyl acetate & Follows zero order kinetics with lowering gastric emptying time & [21] \\
\hline
\end{tabular}

\section{Classification of floating drug delivery systems}

\section{(A) Effervescent system floating drug delivery system}

These are particular drug delivery system made up of matrix type and a swellable polymer such as methylcellulose and chitosan along with effervescent compounds viz. sodium bicarbonate, tartaric acid, citric acid. These are formulated in such a specific way as once it comes in contact with gastric juice; $\mathrm{CO}_{2}$ gets liberated with entrapment in swollen hydrocolloid to provide buoyancy for dosage form. The basis of the delivery system is on swellable asymmetric triple layer tablet approach design [22-24].

\section{(B) Gas generating systems}

Low-density FDDS is based on the release of $\mathrm{CO}_{2}$ upon contact with gastric fluids after oral administration. The materials are formulated in such a way that after entering in the stomach, $\mathrm{Co}_{2}$ is librated due to reaction with acidic gastric content and which get entrapped in the gel-based hydrocolloid (fig. 2). It produces an upward motion of the dosage form and maintains its buoyancy. Ultimately it causes a decrease in specific gravity of dosage form and hence resulting into a float on the chime. The $\mathrm{Co}_{2}$ generating components are mixed within the tablet matrix in a single layer or multi-layered form to produce gas generating mechanism in hydrocolloid layer, and the drug in the other layer results into a sustained release effect $[22,25]$.

\section{(II) Volatile liquid containing systems (Osmotically controlled drug delivery system)}

This is an osmotically controlled floating system in which a device comprised of a hollow deformable unit in convertible collapsed form. Housing would be attached to its deformable unit and internally divided into a first and second chamber separated by an impermeable, pressure sensitive movable unit. The first chamber usually contains an active drug, while the second a volatile liquid, such as cyclopentane or ether get vaporized at a physiological temperature to produce a gas, enabling the drug reservoir to float. The unit gets expelled from the stomach, with the help of bioerodible plug that allowed the vapour to escape [22, 25].

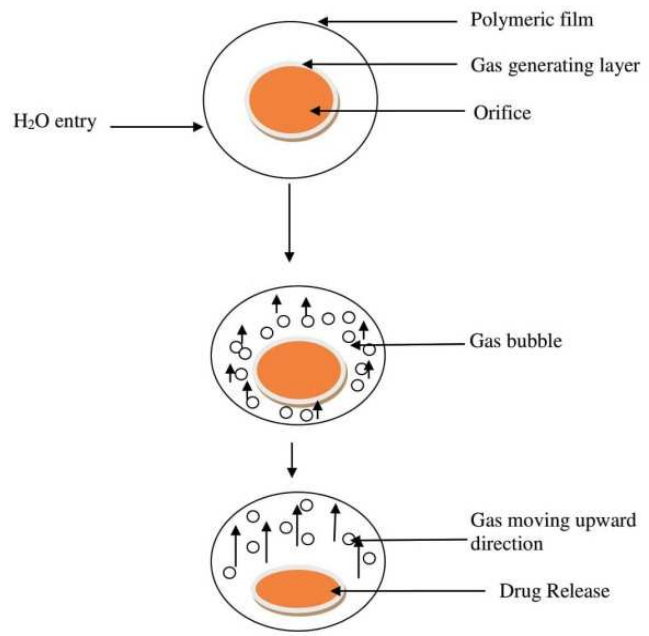

Fig. 2: Mechanism of floatation via $\mathrm{CO}_{2}$ liberation 


\section{(B) Non-effervescent FDDS}

Non-Effervescent Floating Drug Delivery Systems comprises a gel-forming (or) swellable cellulose type of hydrocolloids made up of polysaccharide along with matrix forming polymers like polycarbonate, polymethacrylate, and polystyrene. The routine formulation method involves the mixing of the drug with gel forming hydrocolloids that swell in contact with gastric fluid upon oral administration and maintains the integrity of shape and a bulk density barrier, the air trapped by swollen polymer confer buoyancy to the dosage forms $[22,25]$.

\section{(I) Colloidal gel barrier systems (Hydrodynamic balanced systems)}

This system prolongs gastric retention time and maximizes the amount of drug that reaches its absorption site in the solution form. It essentially contains drug with gel-forming hydrocolloids to remain buoyant on the stomach content. Such a system incorporates one or more gel-forming cellulose type hydrocolloid e. g. hydroxypropyl methylcellulose (HPMC), polysaccharides and matrix forming polymers such as polycarbophil, polystyrene, and polyacrylate. Upon contact with gastro-Intestinal (GI) fluid, the hydrocolloid in the system hydrates to generate a colloid gel barrier to its surrounding $[22,25]$.

\section{(II) Microporous compartment systems}

This technology incorporates the encapsulation technique of a drug reservoir inside a microporous compartment along with pores at top and bottom walls. The peripheral wall of the drug reservoir compartment is completely sealed to prevent any direct contact of the gastric surface with the undissolved drug. In the stomach, the floatation chamber composed of entrapped air causes the delivery system to float over the gastric content. Gastric fluid enters through the aperture, to the extent that it prevents theirs exist from the drug and carrier the dissolved drug for continuous transport across the intestine for absorption [25].

\section{(III) Floating Microspheres/Micro balloons}

Hallow microspheres also are known as micro balloons are considered as a most efficient buoyant system. It is composed of central hallow space inside the microsphere. Hallow microsphere is loaded with a drug in their outer polymer shelf are fabricated by a novel solvent Diffusion method for emulsion [24].

\section{(IV) Alginate beads/Floating beads}

Multi-unit floating dosage forms have been developed from calcium alginate spherical beads of about $2.5 \mathrm{~mm}$ in diameter and can be fabricated by adding sodium alginate solution into aqueous solution of calcium chloride, resulting in the precipitation of calcium alginate, the beads are further separated, snap-frozen in liquid nitrogen and freeze-dried at $400{ }^{\circ} \mathrm{C}$ for $24 \mathrm{~h}$, leads to generation of a porous system. This fabricated system would maintain a floating force for over $12 \mathrm{~h}$ and these floating beads provide a longer residence time of more than $5.5 \mathrm{~h}$ [25].

\section{(C) Raft-forming systems}

Raft-forming systems are in much attention for the delivery of antacid and drug delivery for gastro infection and disorders. On contact with gastric fluid, a gel-forming solution swells and forms a viscous cohesive gel entrapped with $\mathrm{co}_{2}$ bubbles which generate raft layer on top of gastric fluid, thus facilitates releases drug slowly in the stomach [25].

Drugs which are prepared in the floating drug delivery system and their types of dosage forms are given in the table 3.

\section{Table 3: List of drugs explored in floating dosage forms}

\begin{tabular}{|c|c|c|}
\hline $\begin{array}{l}\text { Types of } \\
\text { dosage forms }\end{array}$ & Drugs explored in floating dosage forms & References \\
\hline Microspheres & Aspirin, Griseofulvin, P-nitroaniline, Ibuprofen, Ketoprofen, Terfenadine, Tranilast. & [6] \\
\hline Granules & Diclofenac sodium, Indomethacin, Prednisolone. & {$[6,8]$} \\
\hline Films & Cinnarizine, (capsules) & [8] \\
\hline Capsules & $\begin{array}{l}\text { Chlordiazepoxide } \mathrm{HCl} \text {, Diazepam, Furocemide, L-Dopa and Benserazide, Misoprostol, Nicardipine, Propranolol } \\
\mathrm{HCl} \text {, Ursodeoxychoric acid }\end{array}$ & {$[6,8,10]$} \\
\hline Tablets/Pills & $\begin{array}{l}\text { Acetaminophen, Aspirin, Amoxycillin trihydrate, Ampicillin, Atenolol, Captopril, Ciprofolxacin, Chlorpheniramine } \\
\text { maleate, Cinnarizine, Furosemide, 5-Fluorouracil, Isosorbide mononitrate, Diltiazem, Isosorbide dinitrate, } \\
\text { Nimodipine, Para amino benzoic acid, Prednisolone, Quinidine, Varapamil HCl, Riboflavin, Sotalol. }\end{array}$ & {$[6,8,10]$} \\
\hline Alginate beads & Diclofenac sodium, Famotidine, Nevirapine, Riboflavine, Pantoprazole & [10] \\
\hline $\begin{array}{l}\text { in-situ colloidal } \\
\text { gels }\end{array}$ & Clarithromycin, Furosemide, Ofloxacin & {$[8,10]$} \\
\hline Films & 5-Flurouracil, Propranolol, Metoprolol & {$[8,10]$} \\
\hline
\end{tabular}

Factors affecting gastric residence time of the floating drug delivery system

\section{Formulation factors}

\section{Size of tablets}

Floating retention phenomenon of dosage forms in the stomach basically depends on the size of tablets. Small tablets are expelled rapidly from the stomach compared to large ones are emptied during the digestive phase.

\section{Density of tablets}

Density also considered as contributing factor affecting the gastric residence time of dosage form. A buoyant dosage with a density less than that of the gastric fluids would float as it is long enough from the pyloric sphincter, thus having more retention in the stomach for a longer period. Density tablets about $1.0 \mathrm{~g} / \mathrm{ml}$ (usually considered as less dense than that of gastric contents) have been reported more effective. However, the floating force kinetics has shown that the bulk density of a dosage form would not be the crucial parameter affecting its buoyancy capabilities.

\section{Shape of tablets}

The shape of the dosage form is also considered as one of the affecting factors as it interferes with gastric residence time. Six different types of shapes viz. ring tetrahedron, cloverleaf, string, pellet, and disk) are screened in vivo for their gastric retention potential; during this study, the tetrahedron shape (each leg $2 \mathrm{~cm}$ long) rings ( $3.6 \mathrm{~cm}$ in diameter) passed nearly $100 \%$ retention at $24 \mathrm{~h}$.

\section{Viscosity of polymers}

Drug release and floating characters of FDDS are majorly affected by the viscosity of different grade of polymers and their interaction. Low viscosity polymers (e. g., HPMC K100 LV) are found to be more beneficial than high viscosity polymers (e. g., HPMC K4M) in enhancing the floating properties of the dosage form. Moreover, a decrease in the release rate was also found with an increase in polymer viscosity.

\section{Idiosyncratic factors}

\section{Gender}

A study shows women have slower gastric emptying time in comparison with men. Mean ambulatory gastric retention time in men $(3.4 \pm 0.4 \mathrm{~h})$ is lower in comparison with their age and race with female counterparts $(4.6 \pm 1.2 \mathrm{~h})$, regardless of the weight, height and body surface.

\section{Age}

Lower gastric emptying time is also observed with high frequent in elderly than do in younger. Intra and inter-person variations are also 
existing in gastric and intestinal transit time. Elderly people, especially those over 70 y have a significantly longer gastric retention time.

\section{Posture}

\section{Upright position}

An upright position prolongs floating forms against postprandial emptying since the floating form remains above the gastric contents irrespective of its size [13]. Floating dosage forms show longer and reproducible gastric retention time while the conventional dosage forms tend to sink at the lower part of the distal stomach from where they are expelled through the pylorus by peristaltic movements.

\section{Supine position}

This position does not offer any reliable protection against early and erratic emptying. In supine subjects, large dosage forms (both conventional and floating) may experience longer retention. The gastric retention of floating forms appears to remain buoyant anywhere between the lesser and greater curvature of the stomach. On moving distally, these units may be swept away by the peristaltic movements that propel the gastric contents towards the pylorus, leading to a significant reduction in gastric retention time compared with upright subjects.

\section{Concomitant intake of drugs}

Different drugs with a concomitant intake like prokinetic agents (e. g., metoclopramide and cisapride), anticholinergic (e. g., atropine or propantheline), opiates (e. g., codeine) may affect the performance of the floating drug delivery system. The co-administration of GI motility decreasing drugs can increase gastric emptying time and vice versa.

\section{Feeding regimen}

Gastric residence time shows enhancement in the presence of food, leading to increased drug dissolution rate of the dosage form at the favorable site of absorption. A gastric retention time of about 4 to 10 $\mathrm{h}$ has been reported after a diet of fats and proteins [26-28].

\section{The mechanism associated with FDDS}

FDDS is one of the presidential approaches in achieving gastric retention with sufficient drug bioavailability. This system is selective for the drugs with an absorption window in the stomach or in the upper small intestine. This has a less density then gastric fluids and hence remain buoyant in the stomach without affecting gastric emptying rate for a prolonged period, and the drug is released slowly as a desired rate from the system. After the release of the drug, the residual system is expelled from the stomach. This results in an increased gastric retention time and better control on the fluctuation in plasma drug concentration [29-32].

\section{Pharmacokinetic and pharmacodynamic aspects of FDDS}

\section{Enhanced bioavailability}

FDDS has studied with excellence increase in bioavailability of certain drugs with low therapeutic window solely due to poor GI absorption due to various factors contributing to lower bioavailability. The drugs those considered with narrow absorption window, FDDS shown the possibility of with enhanced bioavailability of the compound to the specific site needed. The bioavailability of control release (CR) floating systems of Riboflavin and Levodopa are significantly enhanced in comparison to the administration of the conventional formulation. On the other hand, CR polymeric formulations of certain bisphosphonates, including alendronate, are absorbed directly from the stomach. However, the magnitude of this pathway remains modest even in the case where the prolonged gastric retention of the bisphosphonate in rats is produced by experimental/surgical means. It may be concluded that several different processes, related to absorption and transit of the drug in the gastrointestinal tract, act concomitantly and influence the magnitude of drug absorption.

\section{Enhanced first-pass biotransformation}

In a similar fashion to increased efficacy of active transporters exhibiting limited capacity activity, the pre-systemic metabolism of the tested compound has considerably increased cause of FDDS, if the drug is presented to the metabolic enzymes (cytochrome P450, in particular, CYP3A4) in a sustained manner, rather than by a bolus input. Improved bioavailability due to reduced P-glycoprotein (P-gp)
activity in the duodenum

In apparent contrast to the higher density of CYP3A4 at the upper part of the intestine, P-gp mRNA levels increase longitudinally along the intestine such that the highest levels are located in the colon. Therefore, for drugs that are P-gp substrate and do not undergo oxidative metabolism, such as Digoxin, floating systems may elevate absorption compared to the immediate and control release (CR) dosage forms.

\section{Reduced frequency of dosing}

The different studies reveal that the drugs those contributing relatively short biological half-life, slow input from sustained release and control release floating system flip-flop pharmacokinetics assured with reduced dosing frequency were observed. This feature is associated with improved patient compliance, and thereby improves therapy.

\section{Targeted therapy for local ailments in the upper GIT}

The prolonged and sustained administration of the drug from the floating systems to the stomach may be advantageous for local therapy in the stomach and the small intestine.

\section{Pharmacodynamic aspects of FDDS}

\section{Reduced fluctuations of drug concentration}

Floating system of drug administration produces constant blood drug concentrations within a narrower range in comparison to the immediate release dosage forms on continuous input of the drug. Thus, fluctuations in drug effects are minimized, and concentrationdependent adverse effects that are associated with peak concentrations can be prevented. This feature is especially advantageous for drugs with a narrow therapeutic index.

\section{Improved selectivity in receptor activation}

Minimization of fluctuations in drug concentration also makes it possible to obtain certain selectivity in the elicited pharmacological effect of drugs that activate different types of receptors at different concentrations.

\section{Reduced counter-activity of the body}

In many cases, the pharmacological response, which intervenes with the natural physiologic processes, provokes a rebound activity of the body that minimizes drug activity. Slow input of the drug into the body as in case of FDDS is shown to minimize the counter activity leading to higher drug efficiency.

\section{Minimized adverse activity at the colon}

Retention of the drug in the FDDS specifically in case of gastro retentive form at the stomach minimizes the amount of drug that reaches down the colon. Thus, undesirable activities of the drug in colon may be prevented. This pharmacodynamic aspect provides the rationale for floating formulation for beta-lactam antibiotics that are absorbed only from the small intestine and presence in the colon leads to the development of microorganisms [31].

\section{Evaluation of floating drug delivery system}

\section{Shape of tablets}

Compressed tablets designed for FDDS are examined under the magnifying lens for the determination of its shape consistency.

\section{Tablet dimensions}

As per official compendia, the thickness and diameter of tablets in FDDS form are measured using a calibrated Vernier callipers same with that of conventional tablets. Three tablets of each formulation are picked randomly, and thickness is measured individually.

\section{Determination of hardness of the tablet}

Randomly sampled twenty tablets in each batch of formulations should be used for the determination of hardness with the help of Monsanto type hardness tester. 


\section{Determination of weight variation}

Twenty tablets selected at random are weighed accurately, and the average weight of the tablet is calculated. Then the deviation of individual weight from the average weight is calculated.

\section{Determination of thickness of the tablet}

The individual crown to crown thickness of ten tablets is determined using slide calipers for each batch

\section{Measurement of floating capacity}

Three individual tablets are put in an individual flask containing 400 $\mathrm{ml}$ of $0.1(\mathrm{~N}) \mathrm{HCL}$ solutions. Then the time in minutes for each tablets to go from the bottom to the top of the flask (floating lag time) and the time for which tablets constantly float on the water surface (duration of floating) are measured. The sample mean and standard deviation are then calculated

\section{Measurement of the density of the formulation}

The apparent densities of the tablets are calculated from their volumes and masses in triplicate. The volume $\mathrm{V}$ of the cylindrical tablets are calculated from their height $h$ and radius $r$ (both determined with a micrometer gauge) using the mathematical equation for a cylinder $\left(\mathrm{V}=\mathrm{A} \times \mathrm{r}^{2} \times \mathrm{h}\right)$.

\section{Determination of drug content in tablets}

Ten tablets from each batch are selected randomly and transferred to a $100 \mathrm{ml}$ volumetric flask filled up with 0.1(N) HCL. Stir and Keep it aside for $2 \mathrm{~h}$ then take $1 \mathrm{ml}$ from the volumetric flask and transfer it to the test tube. Samples are then filtered, suitably diluted and analyzed spectrophotometrically at a suitable wavelength $[32,33]$.

\section{In vitro dissolution study}

The tablet was placed inside the dissolution vessel. $5 \mathrm{ml}$ of sample is withdrawn at time intervals of $1 \mathrm{~h}, 2 \mathrm{~h}, 3 \mathrm{~h}, 4 \mathrm{~h}, 5 \mathrm{~h}, 6 \mathrm{~h}, 8 \mathrm{~h}, 10 \mathrm{~h}$, and $12 \mathrm{~h}$ or any other time intervals as needed. The volume of dissolution fluid adjusted to $900 \mathrm{ml}$ by replacing fresh $5 \mathrm{ml}$ of dissolution medium after each sampling. The release studies were conducted with " $n$ " tablets, and the mean values are plotted versus time. Each sample is analyzed at maximum wavelength using UV visible spectrophotometer against a reagent blank and the corresponding concentration is determined from the respective calibration curve [34].

\section{Buoyancy/Floating test}

The time between introduction of the dosage form and its buoyancy on the simulated gastric fluid and the time during which the dosage form remain buoyant are measured. The time taken for the dosage form to emerge on the surface of a medium called floating lag time (FLT) or buoyancy lag time (BLT) and total duration of time by which dosage form remain buoyant is called total floating time (TFT) [35].

\section{Swelling study}

The swelling behavior of a dosage form is measured by studying its weight gain or water uptake. The dimensional changes could be measured in terms of the increase in tablet diameter and/or thickness over time. Water uptake can be measured in terms of percent weight gain, as given by the equation.

$$
W U=(W t-W o) \times 100
$$

Where,

\section{WU= Water uptake}

$\mathrm{Wt}=$ Weight of dosage form at time $\mathrm{t}$.

Wo = Initial weight of dosage form [35].

\section{CONCLUSION}

Drug absorption in the gastrointestinal tract is a highly variable procedure and prolonging gastric retention of the dosage form that leads to extend the time for drug absorption. FDDS promises to be a potential approach for gastric retention. Numbers of commercial products and patents issues in these fields are the evidence of it. The aim is to improve the bioavailability of the drug with narrow absorption window in gastrointestinal tract region. By prolonging the drug resident time in GI region improves the solubility of drug that is less soluble in high $\mathrm{pH}$ and reduces drug waste, reduction in plasma level fluctuation. Although there are a number of difficulties to be worked out to achieve prolonged gastric retention, a large number of companies are focusing toward commercializing this technique.

\section{AUTHORS CONTRIBUTION}

All the authors have contributed equally

\section{CONFLICT OF INTERESTS}

There is no conflict of interest from all the authors

\section{REFERENCES}

1. Arora S, Ahuja A. Floating drug delivery system: a review. J AAPS PharmSciTech 2005;6:372-90.

2. Deshpande A, Rhodes C, Shah N, Malick A. Controlled-release drug delivery systems for prolonged gastric residence: an overview. Drug Dev Ind Pharm 1996;22:631-9.

3. Hwang S, Park H, Park K. Gastric retentive drug-delivery systems. Crit Rev Ther Drug Carr Syst 1998;15:243-83.

4. Degen L, Peng F, Collet A, Rossi L, Ketterer S, Serrano Y, et al. Blockade of GRP receptors inhibits gastric emptying and gallbladder contraction but accelerates small intestinal transit. Gastroen 2001;120:361-8.

5. Kydoneius A. Controlled release technologies. 2nd Ed. New York: Marcel Dekker; 1991. p. 109.

6. Petrakis I, Kogerakis N, Vrachassotakis N, Stiakakis I, Zacharioudakis G, Chalkiadakis G. Hyperglycemia attenuate erythromycin-induced acceleration of solid phase gastric emptying in healthy subjects. Abd Imag 2002;27:309-14.

7. Silang R, Regalado M, Cheng T, Wesson D. Prokinetic agents increase plasma albumin in hypoalbuminemia chronic dialysis patients with delayed gastric emptying. J Kidney Dis 2001;37:287-93.

8. Garg S, Sharma S. Gastroretentive drug delivery system, Business Briefing: Pharmatech. $5^{\text {th }}$ Edition; 2003. p. 160-6.

9. Singh, Chaudhary V. Preparation of eudragit E100 microspheres by a modified solvent evaporation method. Acta Pol Pharm 2011;68:975-80.

10. Meka L, Kesavan B, Chinnala K, Vobalaboina V, Yamsani M. Preparation of a matrix type multiple-unit gastro-retentive floating drug delivery system for captopril based on gas formation technique: in vitro evaluation. AAPS Pharm Sci Tech 2008;9:612.

11. Hussein O, Mahmoud M, Azza A, Shereen H. Formulation of risperidone in floating microparticles to alleviate its extrapyramidal side effects. Fut J Pharm Sci 2016;2:43-59.

12. Zhang $\mathrm{C}, \mathrm{Xu} \mathrm{M}$, Tao X, Tang J, Liu Z, Zhang Y, et al. A floating multiparticulate system for ofloxacin based on a multilayer structure: in vitro and in vivo evaluation. Int J Pharm 2012;430:141-50.

13. Shinde A, Waghule A, Paithane M, More H. Formulation and in vitro evaluation of sustained release floating tablet of cephalexin using hydrophilic polymers. Int J Pharm Pharm Sci 2010;2:58-65.

14. Hasnain M, Rishiwar P, Sadath A. Floating bioadhesive matrix tablets of hydralazine HCL made of cashew gum and HPMC K4M. Int J Pharm Pharm Sci 2017;9:124-9.

15. Manjunath P, Satish C, Vasanti S, Preetham A, Naidu R. Formulation and evaluation of the simvastatin gastro retentive drug delivery system. Int J Appl Pharm 2017;9:55-60.

16. Tekade B, Jadhao U, Patil S, Patil V. Formulation and in vitro evaluation of floating tablets of cefpodoxime proxetil. Int J Curr Pharm Res 2017;9:18-22.

17. Gunjal P, Shinde M, Gharge V, Pimple S, Gurjar M, Shah M. Design, development and optimization of s (-) Atenolol floating sustained release matrix tablets using surface response methodology. Ind J Pharm Sci 2015;77:563-72.

18. Agarwal S, Zamil F, Singh L, Saxena A. Formulation and evaluation of floating beads of Diltiazem HCl. Int J Curr Pharm Res 2016;8:38-42. 
19. Chavda H, Patel C. Chitosan super porous hydrogel compositebased floating drug delivery system: a newer formulation approach. J Pharm Bioalli Sci 2010;2:124-31.

20. Durgapal S, Mukhopadhyay S, Goswami L. Preparation, characterization and evaluation of floating microparticles of ciprofloxacin. Int J Appl Pharm 2017;9:1-8.

21. Strubing S, Metz H, Mader K. Characterization of poly (vinyl acetate) based floating matrix tablets. I Controlled Release 2008;126:149-55.

22. Timmermans J, Moes A. How well floating dosage do forms float? Int J Pharm 1990;62:207-16.

23. Yang L, Fassihi R. Zero-order release kinetics from selfcorrecting floatable configuration drug delivery system. J Pharm Sci 1996;85:170-3.

24. Burns S, Attwood D, Barnwell SG. Assessment of a dissolution vessel designed for use with floating and erodible dosage forms. Int J Pharm 1998;160:213-8.

25. Joseph N, Laxmi S, Jayakrishnan A. A floating type oral dosage form for piroxicam based on hollow microspheres: in vitro and in vivo evaluation in rabbits. J Controlled Release 2002;79:71-9.

26. Sheth $\mathrm{P}$, Tossounian I. Sustained release pharmaceutical capsules. US patent 1978;4:126-672.

27. Soppimath K, Kulkarni A, Rudzinski W, Aminabhavi T. Microspheres as a floating drug delivery system to increase the gastric residence of drugs. Drug Metab Rev 2001;33:149-60.
28. Ichikawa M, Watanabe S, Miyake Y. A new multiple unit oral floating dosage system. I: prepration and in vitro evaluation of floating and sustained-release kinetics. J Pharm Sci 1991;80:1062-6.

29. Chawla G, Gupta P, Koradia V, Bansal AK. Gastroretention: a means to address regional variability in intestinal drug absorption. Pharm Tech 2003;27:50-68.

30. Chandel A, Chauhan K, Parashar B, Kumar H, Arora S. Floating drug delivery systems: a better approach. Int Curr Pharm ] 2012;1:110-8.

31. Rubinstein A, Friend DR. Specific delivery to the gastrointestinal tract. In: AJ Domb. (Ed.). Polymeric site-specific pharmacotherapy, Wiley, Chichester; 1994. p. 282-3.

32. Vyas SP, Roop KK. Controlled drug delivery concepts and advances. First Edition, New Delhi; 2002. p. 196-217.

33. Harshal S, Chetan G, Surbhi U, Sujit P. Development and in vitro evaluation of an oral floating tablet of metronidazole. J Drug Delivery Ther 2018;8:83-6.

34. Goyal M, Prajapati R, Purohit KK, Mehta SC. Floating drug delivery system. J Curr Pharm Res 2011;5:7-18.

35. Klausner E, Sara E, Lavy E, Friedman M, Hoffman A. Novel levodopa gastro-retentive dosage form: in vivo evaluation in dogs. J Controlled Release 2003;88:117-26. 